\title{
Power Calibration of the TRIGA Mark I Nuclear Research Reactor
}

This paper presents the results and methodology used to calibrate the thermal power of the TRIGA Mark I IPR-RI Research Reactor at the Nuclear Technology Development Centre (CDTN), in Belo Horizonte, Brazil. The TRIGA Mark I is a pool type reactor, cooled by water natural convection. The method used in the calibration consisted in the steady-state energy balance of the primary cooling loop of the reactor. For this balance, the inlet and outlet temperatures and the water flow in this primary cooling loop were measured. The heat transferred through the primary loop was added to the heat leakage from the reactor pool. The thermal losses from the primary loop were not evaluated since the inlet and outlet temperatures were measured just above the water surface of the reactor pool. The temperature of the water in the reactor pool as well as the reactor room temperature were set as close as possible to the soil temperature to minimize heat leakages. These leakages are mainly due to the conduction through the concrete and metal walls and also due to the evaporation and convection through the water surface of the reactor pool.

Elias B. Tambourgi eliastam@desq.feq.unicamp.br State University of Campinas - UNICAMP Faculdade de Engenharia Química Caixa Postal 6066

13083-970 Campinas, SP. Brazil

\section{Introduction}

The TRIGA Mark I IPR-R1 Nuclear Reactor is a pool type reactor, designed for research, training and radioisotope production. The fuel elements at the reactor core are cooled by water natural convection. The heat removal capability of this process is great enough for safety reasons at the current maximum $250 \mathrm{~kW}$ power level of the reactor (Veloso, 1999 and Huda et al, 2001). However, a heat removal system is provided for removing heat from the reactor pool water, as show in Figure 1. The water is pumped through a heat exchanger, where heat is transferred from the primary to the secondary loop. The secondary loop water is cooled in an external cooling tower.

Over the many years since the first TRIGA reactor was built, a number of methodological variations have been evolved for the calibration of the reactor thermal power. The reactor power can be determined from measuring the absolute thermal neutron flux distribution across the core in horizontal and vertical planes. Flux distributions are measured with activation of cadmium covered and bare foils irradiated at steady reactor power (Souza et al., 2002). But it should be noted that this method is time consuming and not accurate (Shaw, 1969). This method is practical only for zero power reactors and in practice it is very seldom performed for other reactors (for the TRIGA IPR-R1 Reactor absolute thermal flux distribution was not performed since reactor rebuilding in 1976).

Power monitoring of nuclear reactors is always done by means of neutronic instruments, but its calibration is done by thermal procedures, (Zagar et al., 1999, Jones. Elliott, 1974 and Verri, 1974).

Thermal power calibrations of low power research reactors (up to $1 \mathrm{MW}$ ) are normally performed during the initial start-up and their results are used for many years. However, some more fuel rods were added in the core to compensate fuel burning along the years, changing the neutron flux distribution. Moreover, new experimental devices introduced in the reactor pool have changed the overall heat capacity of the system. So it became necessary to calibrate the system annually with the presence of all devices in the core and

Paper accepted April, 2007. Technical Editor: Clovis R. Maliska.

A preliminary version of this paper was presented at the 17 th International Congress of Mechanical Engineering, São Paulo, SP, Brazil. around it, as accurate power is important for many irradiation experiments.

General Atomic, the TRIGA reactor constructor, traditionally used a methodology for thermal calibration based on the use of a calibrated electrical heater in a calorimetric procedure (Whittemore et al., 1988) at the startup of a number of its facilities. In this methodology the rate of rise of the bulk pit water temperature was measured when using such heaters. The reactor was then operated to give the same rate of rise of water temperature. Thus the reactor power was established at the value produced by the electrical heaters. The experiment should be performed according to the following procedure: minimize net heat flow through tank walls during the measurement by selecting the initial and final water temperatures to be about equally above and below the average tank wall temperature; operate the reactor at constant power with primary cooling system switched off; install an appropriate stirrer; record the temperature rise of the pool water; determine the temperature-rise rate $(\Delta \mathrm{T} / \Delta \mathrm{t})$; and calculate the reactor power as a function of temperature-rise rate.

For most installations, no stirrer was used in these initial power calibrations. Typically a heater with a $10-15 \mathrm{~kW}$ capacity was used for Mark I and Mark II type reactors. Facilities with larger tanks, such as the 1 MW TRIGA reactor at the Armed Forces Radiological Research Institute (AFRRI), use larger electrical heaters with around $90-100 \mathrm{~kW}$ capacity (Whittemore et al., 1988). In the calibration of the $250 \mathrm{~kW}$ Vienna TRIGA reactor, carried out by Breymesser et al (1995), it was decided to install five submerged electrical heaters at some selected core positions. These submersion heaters have the same form of the original fuel and the total power was $20 \mathrm{~kW}$. It was found that $19.2 \mathrm{kWh}$ of energy was necessary for each $1{ }^{\circ} \mathrm{C}$ of water temperature increase.

In most case, the electrical heater power level was only a tiny fraction of the final reactor power, typically, $10-15 \mathrm{~kW}$ for $250-$ $1000 \mathrm{~kW}$ Mark I or Mark II, giving an output which was only 1.2 $5 \%$ of full power. Even the $90 \mathrm{~kW}$ heaters for the $1000 \mathrm{~kW}$ AFRRI TRIGA reactor gives only about $9 \%$ of the full power. Under these circumstances, the extrapolation from calibration power to full reactor power involves a factor of at least 10 to as high as 20 or more. Such large scale extrapolations require careful attention to the linearity of the power monitor circuitry, especially in the case of water reflected reactors such as the Mark F TRIGA.

After the first few installations of TRIGA reactors, the initial power calibration for later reactors was performed without the 
electrical heaters. With the reactor operating at a constant power, the rate of temperature rise was determined. With a tank constant $(\Delta \mathrm{T}$ per hour per unit power) calculated for the applicable heat content of the system, the reactor power was then determined from the measured rate of temperature rise during the reactor operation. Unfortunately, a stirrer was not used in many of these installations resulting in imperfect mixing during these determinations. Without a stirrer and with intermediate reactor power (100-200 kW), the flow pattern of hot water from the core, with primary cooling system switched off, is a columnar chimney rising up about half way to the surface of the pool and then bending over in a mushroom fashion to return to the region bellow the reactor core. This was observed by Mesquita et al (2002) during the experiments of the IPR-R1 TRIGA Reactor temperature distribution measurement. At a somewhat higher power level $(500-700 \mathrm{~kW})$, this columnar chimney of hot water may extend nearly all the way to the top of the reactor tank before turning over to return to the region below the core (Whittemore et al., 1988). Then it is easy to imagine that the measured rate of temperature rise near the top of the pool can give quite different results depending upon where in the tank the temperature probes were located and whether the chimney reaches all the way to the top of the tank. So it is obviously necessary to provide reproducible temperature measurements that are relatively independent of the location of the temperature probe. A stirrer will homogenize the temperature. It is important to note that the stirring produced by the motor driven impeller assures that all the water in the tank participates in the calorimetric measurement. The small rate of energy added by the pump motor is typically less then $1 \mathrm{~kW}$ and is negligible for power calibrations performed at $200-1000 \mathrm{~kW}$.

The calorimetric procedure is essentially the same whether it involves the calorimetric determination of heat equivalence of electrical energy or the rate of heat generation by a research reactor core. In each case, the calorimeter contains a relatively large volume of water and is constructed with insulated walls to reduce the flow of energy through the calorimeter walls. For the TRIGA system it is obvious, that the heat capacity of the water in the reactor tank is a dominant factor in the whole reactor heat capacity. Zagar et al., (1999) describe that reactor power in research reactors is usually calibrated with an accuracy of $10 \%$ and Whittemore et al. (1988) describe that calorimetric power calibration of TRIGA reactors can be obtained with a precision better than $\pm 5 \%$.

However, this method now presents numerous problems for use in the TRIGA Mark I IPR-R1 Nuclear Reactor. The most important difficulty is the removal of the fuel elements and its substitution for electrical heaters that would be quite complex and onerous, due to the great number of facilities already positioned in the reactor pool, above the core. Another difficulty is the presence of all these facilities that makes it difficult to evaluate the bulk thermal capacity of the reactor pool. Third, and almost as important, is the realization that adequate stirring of the water is necessary in order to provide greater precision in the results of the calibration.

The methodology developed for the thermal power calibration consisted of the measurement of the power dissipated at the primary loop and the calculation of the heat losses. The power dissipated at the cooling loop will be closer to the reactor power the closer the water temperature in the reactor pool is to the environment temperature. It means that the reactor pool temperature must be set close to soil temperature around the pool, and that the air temperature in the reactor room set close to the pool temperature (Mesquita and Rezende, 2001). Therefore, it is important to obtain these conditions and also a stability of the pool temperature over a long period of time, one and a half hours or longer. This can be obtained only after some hours of reactor operation, mainly at night, when there are less changes of the outside air temperature.
The thermal power dissipated in the primary loop can be calculated with a simple thermal balance from the measured values of the inlet and outlet temperatures of the water and its flow rate. We obtain the reactor thermal power by adding this value to the thermal losses. These losses represent a very small fraction of the total power. The power dissipated in the secondary loop was also measured with a thermal balance.

The nuclear power of the TRIGA Mark I IPR-R1 Nuclear Reactor is measured in four different ways:

- The departure channel consists of a fission count with a pulse amplifier that feeds a logarithmic count rate circuit and gives useful power indication from the neutron source level up to a few watts.

- The logarithmic channel consists of a compensated ion chamber feeding a logarithmic $(\log n)$ amplifier and recorder and a period amplifier, which gives a logarithmic power indication on a recorder from less then $0.1 \mathrm{~W}$ to full power.

- The linear channel consists of a compensated ion chamber feeding a sensitive amplifier and recorder with a range switch, which gives accurate power information from source level to full power on a linear recorder.

- The percent channel consists of an uncompensated chamber feeding a power level monitor circuit and meter, which is calibrated in percentage of full power.

The last three channels were adjusted with the results of the thermal calibration described here.

\section{Nomenclature}

$\mathrm{A}=$ area of the upper surface of the reactor pool, $\mathrm{m}^{2}$

$\mathrm{C}_{\mathrm{p}}=$ specfic heat capacity, $\mathrm{J} / \mathrm{kg} .{ }^{\circ} \mathrm{C}$

$\mathrm{C}=$ vapor concentration, $\mathrm{kg} / \mathrm{kg}$ of dry air, dimensionless

$\mathrm{d}=$ thickness of each wall layer, $\mathrm{m}$

$\mathrm{g}=$ acceleration due to gravity, $\mathrm{m} / \mathrm{s}^{2}$

$\mathrm{Gr}=$ Grashof number, dimensionless

$\mathrm{h}=$ depth of the reactor pool, $\mathrm{m}$

$\mathrm{h}_{\mathrm{c}}=$ convective heat transfer coefficient, $\mathrm{W} /\left(\mathrm{m}^{2} \mathrm{~K}\right)$

$\mathrm{h}_{\mathrm{D}}=$ mass-transfer coefficient, $\mathrm{m}^{3} /\left(\mathrm{m}^{2} \cdot \mathrm{s}\right)$

$\mathrm{k}=$ thermal conductivity, $\mathrm{W} /(\mathrm{m} \cdot \mathrm{K})$

$\mathrm{L}=$ characteristic length of the heat transfer surface, $\mathrm{m}$

$\ell=$ height of the water in the pool

$\dot{m}=$ mass flow rate transfer from the pool to the air, $\mathrm{kg} / \mathrm{s}$

$\mathrm{Nu}=$ Nusselt number, dimensionless

$\mathrm{P}=$ thermal power, $\mathrm{W}$

$\mathrm{Pr}=$ air Prandtl number, dimensionless

$\mathrm{Q} 1=$ heat losses through the lateral walls, W

Q2 = heat losses through the bottom, W

$\mathrm{q}_{\mathrm{c}}=$ heat losses due to the convection, $\mathrm{W}$

$\mathrm{q}_{\mathrm{ev}}=$ heat losses due to the evaporation, $\mathrm{W}$

$\mathrm{q}_{\mathrm{m}}=$ flow rate, $\mathrm{kg} / \mathrm{s}$

$\mathrm{R}=$ thermal resistance, $\mathrm{K} / \mathrm{W}$

$\mathrm{r}=$ radius, $\mathrm{m}$

$\mathrm{S}=$ uncertainty, $\mathrm{W}$

$\mathrm{Sc}=$ Schmidt number, dimensionless

$\mathrm{T}$ = temperature, $\mathrm{K}$

\section{Greek Symbols}

$\beta=$ volumetric thermal expansion coefficient of the air, $K^{-1}$

$\Delta \mathrm{T}=$ difference between the temperatures at the inlet and the outlet of the primary loop, ${ }^{\circ} \mathrm{C}$

$\lambda=$ difference between the specific enthalpy of saturated water and the specific enthalpy of saturated steam at the wet-bulb temperature of the air in the reactor room, $\mathrm{J} / \mathrm{kg}$

$v=$ kinematic viscosity of the air, $\mathrm{m}^{2} / \mathrm{s}$

$\pi=$ mathematical constant 3.14159 , dimensionless

$\rho_{\text {air }}=$ air density, $\mathrm{kg} / \mathrm{m}^{3}$ 


\section{Subscripts}

air relative to air

al relative to aluminum layer

$c$ relative to convective

ce relative to of the external concrete layer

$\mathrm{ci}$ relative to internal concrete layer

cool relative to cooling

$D$ relative to the diameter

$e \quad$ relative to external radius of wall layer

ext relative to external wall of the pool

$i \quad$ relative to internal radius of wall layer

in relative to inlet water with relation of heat exchanger

int relative to internal wall of the pool

$m$ relative to coolant water in the primary loop

out relative to outlet water with relation of heat exchanger

$p$ relative to constant pressure, specific heat of the coolant

sat relative to saturation conditions for the air at the reactor room temperature

ss relative to stainless steel layer

sur relative to water pool surface relative to air at the reactor room

1 relative to the lateral walls of the pool

2 relative to the bottom of the pool

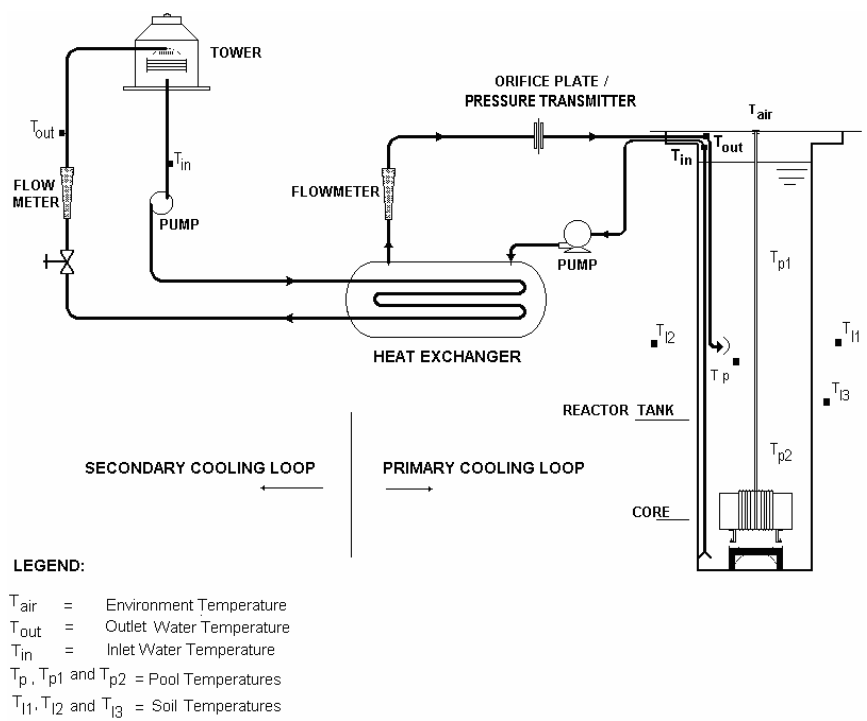

Figure 1. The 250 kW TRIGA Mark I IPR-R1 Research Reactor cooling system with the used instrumentation.

\section{Thermal Power Dissipated in the Primary Loop}

The thermal power dissipated in the primary loop was obtained through a thermal balance given by the following equation:

$\mathbf{P}_{\text {cool }}=\mathbf{q}_{\mathrm{m}} \cdot \mathbf{C}_{\mathrm{p}} \cdot \Delta \mathbf{T}$

Where $q_{m}$ is the flow rate of the coolant water in the primary loop, $C_{p}$ is the specific heat of the coolant, and $\Delta T$ is the difference between the temperatures at the inlet and the outlet of the primary loop.

The data acquisition system registers the following measurements in each second:

- Temperatures in the pool, in the soil around the pool and in the air at the reactor room;

- Temperatures of the water at the inlet and at the outlet of the primary and secondary loops;
- Flow rate of the coolant water in the primary loop.

The data acquisition computer program calculates the power dissipated in the cooling loop with the collected data being used in Equation 1, and with the $q_{m}$ and $C_{p}$ values corrected as function of the temperature of the coolant (Miller, 1989).

\section{Heat Losses from the Reactor Pool to the Environment}

The core of the TRIGA Mark I IPR-R1 Nuclear Reactor is placed below the room floor, in the bottom of a cylindrical pool, $6.625 \mathrm{~m}$ deep and $1.92 \mathrm{~m}$ in diameter, whose upper surface is $25 \mathrm{~cm}$ below the level of the floor. The reactor pool transfers heat to the environment by conduction to the soil, through the lateral walls and through the bottom of the pool, and by convection and evaporation to the air at the reactor room, through the upper surface.

The reactor pool was built as a five layer cylindrical tank, open at the upper side, as shown in Figure 2. The innermost layer, which is in contact with the water, is $10 \mathrm{~mm}$ thick and is made of a special alloy of aluminum (AA-5052-H34). Surrounding it there is a $72 \mathrm{~mm}$ thick layer of concrete and then a $6.3 \mathrm{~mm}$ thick stainless steel layer. After that, another concrete layer $203 \mathrm{~mm}$ thick and finally another stainless steel layer $6.3 \mathrm{~mm}$ thick.

\section{Heat Losses From the Pool to the Soil}

The heat losses through the lateral walls is given by the equation below (Özisik, 1990)

$$
Q 1=\frac{T_{i n t}-T_{e x t}}{R_{a l}+R_{c i}+R_{s s}+R_{c e}}
$$

Where $T_{\text {int }}$ is the average temperature of the internal wall of the pool, $T_{\text {ext }}$ is the average temperature of the soil around the reactor, $R_{a l}$ is the thermal resistance of the aluminum layer, $R_{c i}$ is the thermal resistance of the internal concrete layer, $R_{s s}$ is the thermal resistance of the stainless steel layer and $R_{c e}$ is the thermal resistance of the external concrete layer.

The thermal resistance for cylindrical walls was obtained from the following equation (Özisik, 1990)

$$
R=\frac{\ell}{2 \pi h k} \ln \left(\frac{r_{e}}{r_{i}}\right)
$$

Where $\ell$ is the height of the water in the reactor pool $(6.417 \mathrm{~m})$, $k$ is the thermal conductivity of each material, $r_{i}$ and $r_{e}$ are the internal and external radii of each wall layer.

The heat tr ansfer through the bottom of the pool is obtained from:

$$
Q 2=\frac{T_{i n t}-T_{e x t}}{R_{a l 2}+R_{c i 2}+R_{s s 2}+R_{c e 2}}
$$

The values of the thermal resistance for flat surface section are obtained from the following equation (Özisik, 1990):

$$
R=\frac{d}{A k}
$$

Where $d$ is the thickness of each wall layer and $A$ is the area of the upper surface. 


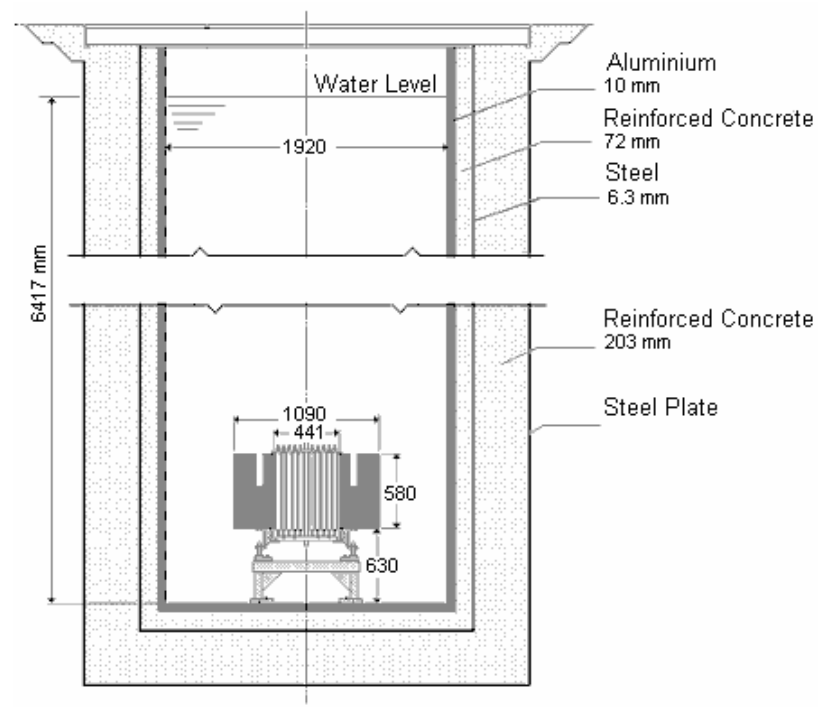

Figure 2. The TRIGA Mark I IPR-R1 nuclear reactor pool.

\section{Heat Losses From the Pool to the Air in the Reactor Room}

The heat losses due to the evaporation in the upper surface of the reactor pool were calculated by the following equation (Holman, 1963):

$$
q_{e v}=\dot{m} \lambda
$$

Where $\lambda$ is the difference between the specific enthalpy of saturated water and the specific enthalpy of saturated steam at the wet-bulb temperature of the air in the reactor room, and $\dot{m}$ is the rate of mass transfer from the pool to the air, given by the equation:

$$
\dot{m}=h_{D} \cdot A \cdot \rho_{\text {air }}\left(C_{\text {sat }}-C_{\infty}\right)
$$

Where $A$ is the upper surface of the reactor pool, $\rho_{\text {air }}$ is the air density, $C_{s a t}$ is the vapor concentration at saturation conditions for the air at the reactor room temperature, $C_{\infty}$ is the vapor concentration in the air in the reactor room and $h_{D}$ is the mass-transfer coefficient given by the following equation:

$$
h_{D}=\frac{h_{c}}{\rho_{\text {air }} \cdot C p_{\text {air }}}\left(\frac{P r}{S c}\right)^{2 / 3}
$$

Where $P r$ is the Prandtl number $\left(0.708\right.$ for the air at $\left.25^{\circ} \mathrm{C}\right), S c$ is the Schmidt number $(0.60$ for water vapor diffusing in the air at $\left.25^{\circ} \mathrm{C}\right), C p_{\text {air }}$ is the heat capacity of the air, $h_{c}$ is the convection heat transfer coefficient, obtained from:

$$
h_{c}=\frac{k}{L} N u
$$

Where $k$ is the thermal conductivity in the air, $L$ is the characteristic length of the heat transfer surface, equivalent to 0.9 times the diameter of the pool or $1.728 \mathrm{~m}$ and $N u$ is the Nusselt number obtained from:

$$
N u=0.14(G r \cdot P r)^{1 / 3}
$$

$G r$ is the Grashof number given by:

$$
G r=\frac{g \cdot \beta \cdot\left(T_{\text {sur }}-T_{\infty}\right) \cdot L^{3}}{v^{2}}
$$

Where $g$ is the acceleration due to gravity, $\beta$ is the volumetric thermal expansion coefficient of the air, $T_{\text {sur }}$ is the water pool temperature at the surface, $T_{\infty}$ is the air temperature in the reactor room and $v$ is the kinematic viscosity of the air.

The relative humidity of the air in the room of the reactor was measured, during the tests. The convection heat transfer through the reactor pool surface was calculated with the following equation (Holman, 1963):

$$
q_{c}=h_{c} \cdot A \cdot\left(T_{\text {sur }}-T_{\infty}\right)
$$

\section{Instrumentation}

Two platinum resistance thermometers (PT-100) were positioned at the inlet and at the outlet pipes of the primary cooling loop, just above the water surface of the reactor pool (see $T_{\text {in }}$ and $\mathrm{T}_{\text {out }}$ in Figure 1). These thermometers, together with a flowmeasuring device at the loop, give the power dissipated through the primary cooling loop. The flow-measuring device consists of an orifice plate and a differential pressure transmitter. This pressure transmitter was calibrated and an adjusted equation was obtained and added to the data acquisition system. The temperature measuring lines were calibrated as a whole, including thermometers, cables, data acquisition cards and computer. The adjusted equations were also added to the data acquisition system.

Two type K thermocouples and one resistance thermometer (PT100) were positioned inside the pool, at different heights, to measure the water pool temperature. A type $\mathrm{K}$ thermocouple was placed just above the pool surface to measure the air temperature at the reactor room. Finally, three type $\mathrm{K}$ thermocouples were distributed around the pool, in three holes in the reactor room floor, to measure the soil temperature. The temperature measuring lines were also calibrated as a whole, including thermocouples or resistance thermometer, cables, data acquisition cards and computer. The equations obtained for each line were also added to the data acquisition system.

For the measurement of the power dissipated in the secondary cooling loop, two resistance thermometers (PT-100) were also positioned in its inlet and outlet pipes. The water flow rate at this loop was maintained constant and was also measured.

The sensor signs were sent to an amplifier and multiplexing board, that also makes the temperature compensation for the thermocouples. These signs were sent to a data acquisition card that makes the analog/digital conversion. This card was installed together in a computer where the data were calculated, registered and recorded (Mesquita, 2003). All data were obtained as the average of 120 readings and were recorded together with their standard deviations. The data acquisition system registers these data each second.

\section{Results}

Initially a thermal power measuring experiment was carried out, with the new reactor core configuration of 63 fuel elements. A thermal power of about $220 \mathrm{~kW}$ was measured when the linear channel was indicating the power of $250 \mathrm{~kW}$. So, the ion chambers were replaced and the power indication instruments at the control panel (linear channel, logarithm channel and percent channel) were adjusted again. Another thermal power measuring experiment was then carried out whose results are presented here.

The reactor operated during a period of about 6 hours with a power of $250 \mathrm{~kW}$ indicated at the linear channel. The power 
dissipated through the primary cooling loop was monitored during the whole test period, and the measured temperatures were stable for $1.5 \mathrm{~h}$ (from 21:00 h to 22:30 h). Figure 3 shows the evolution of the measured temperatures and Figure 4 shows the evolution of the thermal power dissipated in the primary loop, during the period of stability. Table 1 presents the average thermal power obtained in this same period.

The thermal power dissipated through the primary cooling loop was calculated by Equation (1), as mentioned before. Then, its uncertainty was calculated considering the uncertainties at the measured flow rate (ISO 5167, 1980), inlet and outlet temperatures and also at the estimated water heat capacity, as given in the following equation (Figliola and Beasley, 1991):

$$
S=\sqrt{\left(\frac{\partial P}{\partial m} \times S_{q_{m}}\right)^{2}+\left(\frac{\partial P}{\partial C_{p}} \times S_{C_{p}}\right)^{2}+\left(\frac{\partial P}{\partial \Delta T} \times S_{\Delta T}\right)^{2}}
$$

The uncertainties shown in Table 1 were calculated by the data acquisition software considering all these parameters.

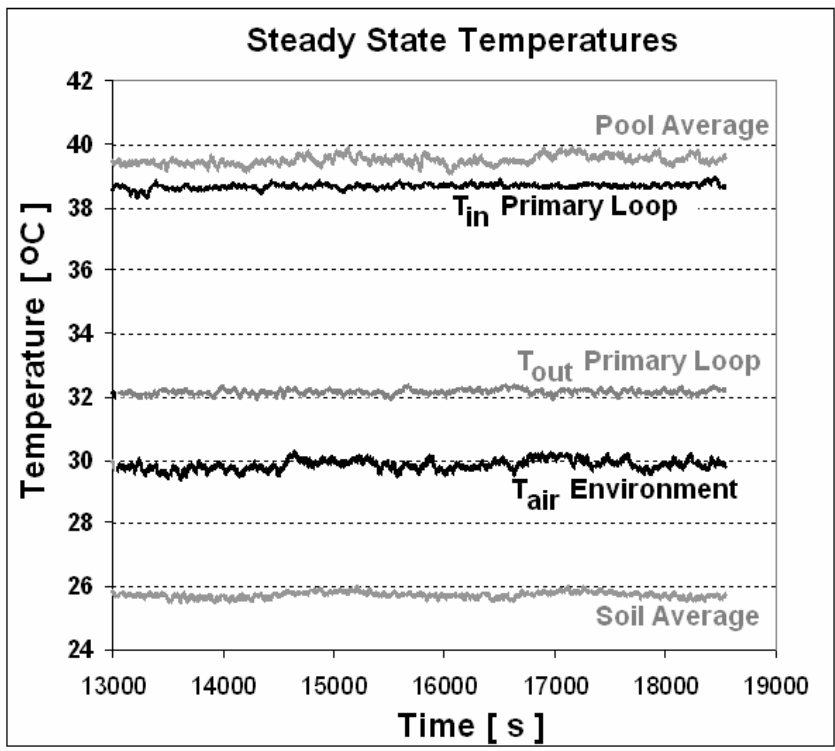

Figure 3. Evolution of the temperatures during the period of stability.

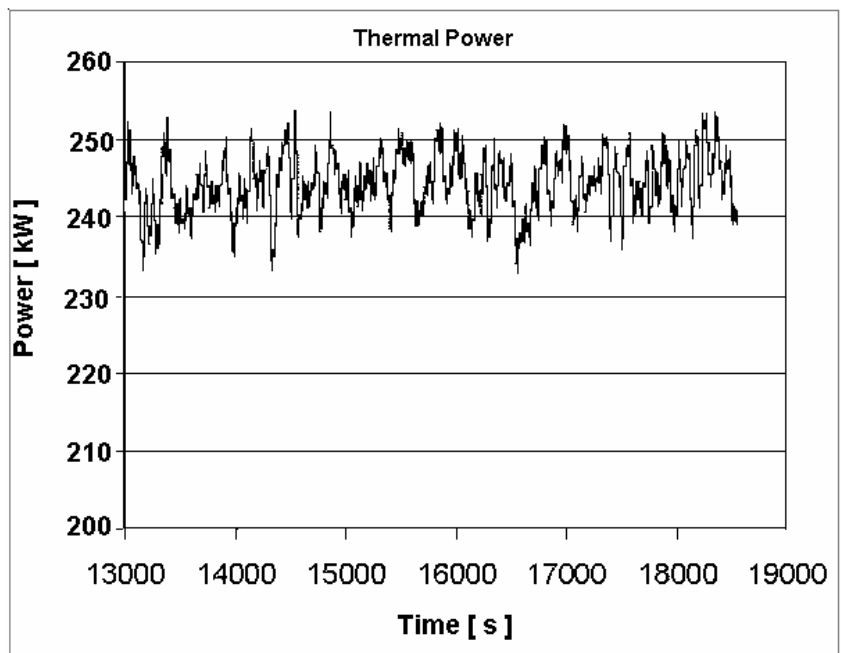

Figure 4. Evolution of the thermal power obtained during the period of stability.
Table 1. Results of the Thermal Power Calibration.

\begin{tabular}{|c|c|c|}
\hline \multicolumn{2}{|c|}{ Average primary loop coolant flow rate } & $32.26 \pm 0.05 \mathrm{~m}^{3} / \mathrm{h}$ \\
\hline \multicolumn{2}{|c|}{ Average primary loop inlet temperature } & $38.7 \pm 0.3{ }^{\circ} \mathrm{C}$ \\
\hline \multicolumn{2}{|c|}{ Average primary loop outlet temperature } & $32.2 \pm 0.2{ }^{\circ} \mathrm{C}$ \\
\hline \multicolumn{2}{|c|}{ Power dissipated in the primary loop } & $244 \mathrm{~kW}$ \\
\hline \multirow{5}{*}{$\begin{array}{l}\text { Thermal } \\
\text { losses from } \\
\text { the reactor } \\
\text { pool }\end{array}$} & Conduction through the wall & $3.04 \mathrm{~kW}(89.4 \%)$ \\
\hline & Conduction through the bottom & $0.25 \mathrm{~kW}(7.3 \%)$ \\
\hline & Evaporation & $0.03 \mathrm{~kW}(1.0 \%)$ \\
\hline & Convection & $0.08 \mathrm{~kW}(2.3 \%)$ \\
\hline & Total & $3.40 \mathrm{~kW}(100 \%)$ \\
\hline \multicolumn{2}{|c|}{ Total reactor power } & $248 \mathrm{~kW}$ \\
\hline \multicolumn{2}{|c|}{ Standard deviation of the readings } & $\pm 3.7 \mathrm{~kW}$ \\
\hline \multicolumn{2}{|c|}{$\begin{array}{l}\text { Uncertainty in the measure of the reactor thermal } \\
\text { power }\end{array}$} & $\pm 14 \mathrm{~kW}( \pm 5.7 \%)$ \\
\hline \multicolumn{2}{|c|}{ Power dissipated in the secondary loop } & $237 \mathrm{~kW}$ \\
\hline
\end{tabular}

\section{Conclusion}

The power of the TRIGA Mark I IPR-RI Nuclear Reactor at CDTN / CNEN was recently increased from $100 \mathrm{~kW}$ to $250 \mathrm{~kW}$. The reactor thermal power calibration is very important for precise neutron flux and fuel element burnup calculations. The burnup is linearly dependent on the reactor thermal power and its accuracy is important to the determination of the mass of burned $U^{235}$, fission products, fuel element activity, decay heat power generation and radiotoxicity.

The calibration method used consisted of the steady-state energy balance of the primary cooling loop. For this balance, the inlet and outlet temperatures and the water flow in this primary cooling loop were measured. The heat transferred through the primary loop was added to the heat leakage from the reactor pool. The thermal losses from the primary loop were not evaluated since the inlet and outlet temperatures were measured just above the water surface of the reactor pool. To minimize the heat leakage the temperature of the water in the reactor pool, as well as the reactor room temperature, were set as close as possible to the soil temperature, since leakage is mainly due to the conduction through the concrete and metal walls to the soil and also due to evaporation and convection through the water surface of the reactor pool.

The heat balance method is accurate, but impractical for monitoring the instantaneous reactor power level, particularly during transients. The power is monitored by four nuclear detectors, which are calibrated by the thermal method described here. This is now the standard procedure for calibrating the power of the TRIGA Mark I IPR-R1 Nuclear Reactor. The values calculated for the uncertainties agree with international results (Zagar et al, 1999).

\section{Acknowledgements}

The authors thank the operation staff of the TRIGA Mark I IPRR1 Nuclear Reactor, for the readiness and dedication in the operation of the reactor during these measurements.

\section{References}

Breymesser, A. et al., 1995, "Thermal Power Calibration of the TRIGA Reactor Wien", Proceedings of the $2^{\text {nd }}$ Regional Meeting: Nuclear Energy In Central Europe, Nuclear Society of Slovenia, Portoroz, pp. 44-47.

Figliola, R.S. and Beasley, D.E., 1991, "Theory and Design for Mechanical Measurements", John Wiley \& Sons, New York.

Holman, J.P., 1963, "Heat Transfer", McGraw-Hill Book Company, New York, $402 \mathrm{p}$

Huda, M.Q. et al, 2001, "Thermal-Hydraulic Analysis of the 3 MW TRIGA Mark-II Research Reactor under Steady-State and Transient Conditions", Nuclear Tecnology, Vol. 135, July, pp. 51-66. 
ISO 5167, 1980 (E), "Measurement of Fluid Flow by Means of Orifice Plates, Nozzles and Venturi Tubes inserted in Circular Cross-Section Conduits running full", International Organization For Standardization.. Switzerland, $35 \mathrm{p}$.

Jones, M. and Elliott, A., 1974, "A Simplified Method of Power Calibration", Proceedings of the $3^{\text {rd }}$ European Conference of TRIGA Users, Munich, pp.4-8 - 4.12.

Mesquita, A.Z. and Rezende H.C., 2001, "Levantamento da Potência Térmica do Reator TRIGA IPR-R1 durante os Testes de Mudança de sua Potência de $100 \mathrm{~kW}$ para $250 \mathrm{~kW}$ ", (CNEN/CDTN NI-IT4-004), Belo Horizonte, $36 \mathrm{p}$.

Mesquita, A.Z., 2003, "Sistema de Aquisição e Tratamento de Dados do Reator Nuclear de Pesquisa TRIGA IPR-R1”, (CNEN/CDTN NI - IT4 003/03, Belo Horizonte, 27 p.

Mesquita, A.Z., Rezende, H.C. and Maretti, J.F., 2002, "Temperature Distribution at the Pool and the Core of the IPR-R1 TRIGA Mark I Reactor", Proceedings of the $1^{\text {st }}$ World TRIGA Users Conference, Università Degli Studi Di Pavia, LENA - Laboratorio Energia Nucleare Applicata - Centro Servizi Interdipartimentale. Pavia, Italy, June $16^{\text {th }}-20^{\text {th }}$.

Miller, R.W., 1989, "Flow Measurement Engineering Handbook", Second Edition. New York, McGraw-Hill Publishing Company, p. E19-E21.
Özisik, M.N., 1990, “Transferência de Calor”, Editora Guanabara, Rio de Janeiro, $661 \mathrm{p}$

Shaw, J., 1969, "Reactor Operation". Pergamon Press, Oxford.

Souza, R.M.G. P. et al., 2002, "Resultados dos Testes Finais para o Aumento de Potência do Reator TRIGA IPR-R1". (CDTN/CNEN NI - IT407/02), Belo Horizonte, 54 p.

Veloso, M.A., 1999, "Análise Termo-Hidráulica do Reator TRIGA IPRR1 a 250 kW”, (NI-CT4-03/99 CNEN/CDTN), Belo Horizonte, 141 p.

Verri, A., 1974, "Power TRIGA Calibration by Thermal Method", Proceedings of the $3^{\text {rd }}$ European Conference of TRIGA Users, Munich, pp. 3-1-3-6.

Whittemore, W.L., Razvi, J. and Shoptaugh, J.R., 1988, "Power Calibrations for TRIGA Reactors", Proceedings of the $11^{\text {th }}$ Biennial U. S. TRIGA User's Conference, Gulf General Atomic, Washington, 10-13 April, pp. 4-114, 4-138.

Zagar, T., Ravnik, M. and Persic, A., 1999, "Analysis of Reactor Thermal Power Calibration Method", Proceedings of the International Conference Nuclear Energy In Central Europe'99, Slovenia, Portoroz, 6 - 9 September, pp. 91-98. 